\title{
Retraction Note to: An investigation on mechanical and metallurgical properties of 2024-T3 aluminum alloy spot friction welds
}

\author{
Moslem Paidar $^{1}$ - Alireza Khodabandeh ${ }^{2}$ - Hamidreza Najafi ${ }^{2}$. \\ Alireza Sabour Rouh-aghdam ${ }^{3}$
}

Published online: 2 June 2017

(C) Springer-Verlag London 2017

\section{Retraction Note to: Int J Adv Manuf Technol DOI 10.1007/s00170-015-6997-2}

The Editor-in-Chief and regional editor have decided to retract the following article: "An investigation on mechanical and metallurgical properties of 2024-T3 aluminum alloy spot friction welds", The International Journal of Advanced Manufacturing Technology, September 2015, Volume 80, Issue 1, pp. 183-197. Upon investigation carried out according to the Committee on Publication Ethics guidelines, it has been found that the authors have duplicated figures from the following article(s) without permission: Figs. 1 and 2 from Journal of Engineering Materials and Technology (10.1115/ 1.4030197), Fig. 3 from Mechanical Science and Technology
28 (12) (2014) 4893-4898, Fig. 4(a) from Mechanical Science and Technology 28(12)(2014)4893-4898, Fig. 4(c) from Mechanical Science and Technology 28(12)2014) 48934898, Fig. 5(a) from Materials and Technology (10.1115/1. 4030197), Fig. 5(a) from Materials and Technology (10. 1115/1.4030197), Fig. 7 (c, e) from Materials and Technology (10.1115/1.4030197), Fig. 8(c) from Materials and Technology (10.1115/1.4030197), Fig. 9 from Materials and Technology (10.1115/1.4030197), Fig. 10 from Journal of Mechanical Science and Technology 28(12)2014)4893-4898, Fig. 11 from data from Journal of Mechanical Science and Technology 28 (12), (2014) 4893-4898, Fig. 12 (a) from Journal of Mechanical Science and Technology, Fig. 17(a) from Materials and Technology (10.1115/1.4030197).

The online version of the original article can be found at http://dx.doi.org/ 10.1007/s00170-015-6997-2

Moslem Paidar

m.paidar@srbiau.ac.ir

1 Department of Materials Engineering, South Tehran Branch, Islamic Azad University, Tehran, Iran

2 Department of Materials Engineering, Science and Research Branch, Islamic Azad University, Tehran, Iran

3 Department of Materials Engineering, Tarbiat Modares University, Tehran, Iran 